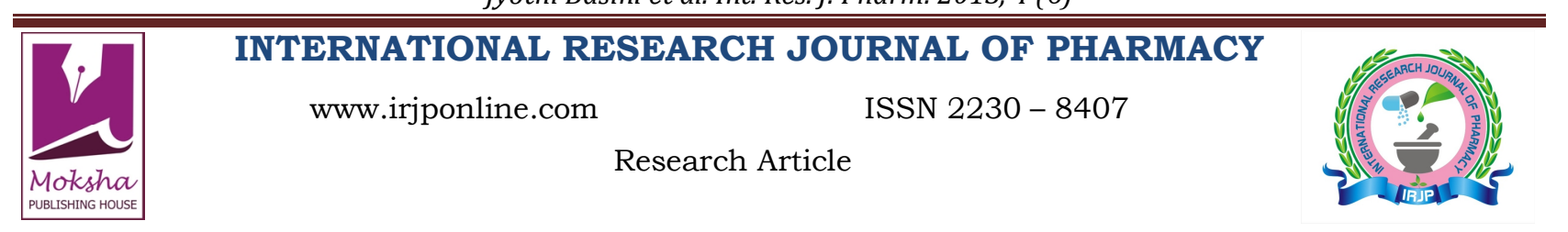

\title{
ANTIHEPATOTOXIC EFFECT OF BARLERIA MONTANA LEAVES AGAINST ANTI-TB DRUGS INDUCED HEPATOTOXICITY
}

\author{
Jyothi Basini*1, S. Mohana lakshmi ${ }^{2}$, K. Anitha ${ }^{2}$ \\ ${ }^{1}$ Department of pharmacology, Krishna Teja Pharmacy College, Chadalawada Nagar, Renigunta road, Tirupathi, Chittoor \\ (Dist), A.P, India \\ ${ }^{2}$ Department of Pharmacognosy, Sree Vidyanikehan College of Pharmacy, Sree Sainath Nagar, A.Rangampet, Tirupathi, \\ Chittoor (Dist), A.P, India \\ *Corresponding Author Email: jyothi_811@yahoo.co.in
}

Article Received on: 14/03/13 Revised on: 01/04/13 Approved for publication: 17/05/13

DOI: $10.7897 / 2230-8407.04621$

IRJP is an official publication of Moksha Publishing House. Website: www.mokshaph.com

(C) All rights reserved.

\begin{abstract}
Introduction: The present study was undertaken to evaluate the protective activity of 95\% hydroalcoholic extract of Barleria Montana leaves against anti-TB drugs induced hepatotoxicity. Methods: Hepatotoxicity was induced by anti-TB drugs once daily for 35 days and simultaneously $95 \%$ hydroalcoholic extract of Barleria Montana (250 \& $500 \mathrm{mg} / \mathrm{kg}$ p.o.) was administered one hour prior administration of anti-TB drugs. Silymarin was used as standard drug (100 $\mathrm{mg} / \mathrm{kg}$ p.o.). Results: Elevated levels of SGOT, SGPT, ALP, TB \& total cholesterol and decreased total HDL following anti-TB drugs administration. Pretreatment of $95 \%$ hydroalcoholic extract of Barleria Montana with anti-TB drugs were significantly reduced biochemical markers and increased total HDL. In vivo antioxidant parameters such as SOD, CAT, GSH, GPx and GRx were suppressed in hepatic control animals. Pre treatment of 95\% hydroalcoholic extract of Barleria Montana with anti-TB drugs significantly reduced lipid per oxidation and increased antioxidant activities. Conclusion: The result of the present study was indicated that Barleria Montana showed protective effect on liver toxicity induced by anti-TB drugs might be attributed to its antioxidant activity.

Key Words: Antihepatotoxic effect, anti-TB drugs, Barleria Montana, Biochemical Markers, In vivo antioxidant parameters.
\end{abstract}

\section{INTRODUCTION}

Liver is a vital organ in the body and it plays an important role for the metabolism of endogenous and exogenous agents. It is the first organ to be exposed to the damaging effects of the newly formed toxic substance during metabolism ${ }^{1}$. As a traditional medicine, plant products are used for the treatment of liver disorders all over the world ${ }^{2}$. Tuberculosis (TB) continues to be a health problem worldwide, WHO estimated 9.27 million new cases of TB in $2007^{3}$. According to DOTS (Directly Observed Treatment Shortcourse), chemotherapeutic regimens of TB involves isoniazid $(\mathrm{H})$, rifampicin $(\mathrm{R})$, pyrazinamide $(\mathrm{Z})$ and/ ethambutol $(\mathrm{E})$ is highly effective. However, hepatotoxicity is a serious adverse drug reaction of these currently used anti-TB drugs ${ }^{4}$. Therefore, a search for an alternative therapy/ supplementation of plant drugs useful for the treatment of hepatotoxicity and also the efforts to explore the mechanism of hepatoprotective effect of natural products thus carry a great clinical significance. Barleria Montana, (Synonym Barleria Purpurea) commonly known as Mountain Barleria has been traditionally used for centuries for treating wounds, diabetes, cough, inflammation and is known to possess hepatoprotective activity. The leaves of Barleria Montana (BM) are reported as having antimicrobial activity, pharmacognostic and physicochemical analysis ${ }^{6}$, antibacterial activity $^{7}$, antidiabetic activity ${ }^{8}$ and proved to possess in-vitro antioxidant activity ${ }^{9}$. Still there is no scientific report on Antihepatotoxic potential of $95 \%$ hydroalcoholic extract of Barleria Montana L. leaves against anti-TB drugs induced hepatotoxicity. Therefore, the present study was undertaken for antihepatotoxic effect of $95 \%$ hydroalcoholic extract of Barleria Montana against anti-TB drugs induced hepatotoxicity in rats.

\section{MATERIAL AND METHODS}

\section{Collection and Authentication of Plant Material}

Leaves of Barleria montana were collected from Tirumala hills, Andhra Pradesh. The plant was identified, authenticated and certified by Dr. K. Madhavachetty, Assistant Professor, Department of Botany, S.V.University, Tirupathi and A.P., India.

\section{Preparation of plant extract}

The air dried powder was extracted in Soxhlet apparatus using 95\% hydroalcoholic solution as solvent. Appearance of colorless solvent in the siphon tube was taken as the endpoint of extraction. The extract was concentrated to $3 / 4$ of its original volume by distillation.

\section{Acute toxicity studies}

Acute toxicity studies were performed for $95 \%$ hydroalcoholic extract of Barleria Montana according to OECD guidelines $423^{10}$. 10 mice were selected for the study and oral administration of $95 \%$ hydroalcoholic extract of Barleria Montana at a dose of 100, 1000, 2000, $4000 \mathrm{mg} / \mathrm{kg}$ given at $48 \mathrm{hrs}$ interval simultaneously. In this acute toxic study, animals were observed for any changes in consumption of food, water; body weight; behavioral changes and mortality rates.

\section{Animals}

Healthy adult albino rats (150-250 gm) were used and they were purchased from In vivo biosciences, Bangalore. The animals were housed in clean metabolic cages, maintained in controlled temperature $\left(22 \pm 3^{\circ} \mathrm{c}\right)$ and light cycle (12 hour light and 12 hour dark). They were fed with standard pellet diet and water ad libitum. The protocol was approved by the Institutional animal ethical committee (IAEC) of Krishna Teja Pharmacy College (1521/PO/a/11/CPCSEA). 
Study protocol

Hepatotoxicity was induced by using H-Isoniazid $(27 \mathrm{mg} / \mathrm{kg}$, p.o), R-Rifampicin (40 mg/kg, p.o), Z-Pyrazinamide (66 $\mathrm{mg} / \mathrm{kg}, \mathrm{p} . \mathrm{o})$ and E-Ethambutol(53 mg/kg,p.o) were dissolved in normal saline for 35 days and Silymarin $(100 \mathrm{mg} / \mathrm{kg}$, p.o) was used as the standard. The oral doses of anti-TB drugs were extrapolated from daily human dose using the conversion table based on body surface area ${ }^{11}$.

\section{Experimental procedure}

Experimental animals were randomly divided in to 5 groups, each group containing 6 animals and the treatment schedule for 35 days as follows. Group I: Control (Normal saline $1 \mathrm{ml} / \mathrm{kg}$, p.o), Group II: Hepatic control (anti - TB drugs HRZE, p.o.), Group III: Silymarin (100 mg/kg, p.o) + one hour prior administration of anti-TB drugs, Group IV: 95\% hydroalcoholic extract of Barleria Montana (250 gm/ $/ \mathrm{kg}$, p.o)+one hour prior administration of anti- TB drugs and Group V: 95\% hydroalcoholic extract of Barleria Montana $(500 \mathrm{gm} / \mathrm{kg}, \mathrm{p.o})+$ one hour prior administration of anti- TB drugs. On $36^{\text {th }}$ day, blood is collected for estimation of biochemical parameters. On the same day, liver is removed and stored in $10 \%$ formalin solution for the estimation of antioxidant parameters; and processing for histopathological studies.

Estimation of Biochemical and Antioxidant Parameters SGOT and SGPT were estimated by Reitman and Frankel method, ALP was estimated by kind king's method. Total Bilirubin, total cholesterol were estimated by Jendrassik and Grofs method and CHOD/POD method respectively. Antioxidant parameters were estimated by according to reported methods $\mathrm{SOD}^{12}, \mathrm{CAT}^{13}, \mathrm{GSH}^{14}, \mathrm{GPx}^{15}, \mathrm{GRx}^{16}$ and lipid peroxidation ${ }^{17}$.

\section{Histopathological studies}

Livers from rats were fixed in $10 \%$ neutral formalin solution, dehydrated in graded alcohol and embedded in paraffin. Fine sections obtained were mounted on glass slides and counterstained with Hematoxylin Eosin (H\&E) for light microscopic analyses.

\section{Statistical analysis}

The results are presented as Mean \pm S.E.M ( $\mathrm{n}=6$ in each group). Analyses were performed using One-way ANOVA followed by Tukey posthoc for the difference between the control and treatment groups.

Table 1: Effect of Barleria Montana on serum SGOT, SGPT, ALP, TB, Total cholesterol and HDL on anti -TB drugs induced hepatotoxicity in rats

\begin{tabular}{|c|c|c|c|c|c|c|c|}
\hline Groups & Treatment & $\begin{array}{l}\text { SGOT } \\
\text { (IU/L) }\end{array}$ & $\begin{array}{l}\text { SGPT } \\
\text { (IU/L) }\end{array}$ & $\begin{array}{c}\text { ALP } \\
\text { (IU/L) }\end{array}$ & $\begin{array}{c}\text { TB } \\
\text { (IU/L) }\end{array}$ & $\begin{array}{c}\text { Total cholesterol } \\
(\mathrm{mg} / \mathrm{dl})\end{array}$ & $\begin{array}{l}\text { HDL } \\
\text { (mg/dl) }\end{array}$ \\
\hline Group-I & Control & $122.67 \pm 6.38$ & $63 \pm 3.02$ & $182 \pm 6.27$ & $0.06 \pm 0.01$ & $83.5 \pm 6.3$ & $33.8 \pm 2.1$ \\
\hline Gropu-II & $\begin{array}{l}\text { Anti-TB Drugs } \\
\text { (Hepatic control) }\end{array}$ & $386.50 \pm 14.60 \#$ & $639.33 \pm 17.96 \#$ & $315.83 \pm 7.46 \#$ & $0.39 \pm 0.01 \#$ & $131.3 \pm 16.2 \#$ & $17.4 \pm 1.9$ \\
\hline Group-III & $\begin{array}{c}\text { Silymarin } \\
(100 \mathrm{mg} / \mathrm{kg})\end{array}$ & $166.67 \pm 2.90 * * *$ & $136.33 \pm 5.76^{*}$ & $138 \pm 9.65^{* * *}$ & $0.08 \pm 0.02^{* *}$ & $88.7 \pm 5.9^{* * *}$ & $33.6 \pm 2.4 * * *$ \\
\hline Group-IV & $\begin{array}{c}\text { Barleria Montana } \\
(250 \mathrm{mg} / \mathrm{kg})\end{array}$ & $277.50 \pm 7.68^{*}$ & $232.67 \pm 7.45^{* *}$ & $205 \pm 5.50^{* *}$ & $0.08 \pm 0.01 * *$ & $116.9 \pm 9.5^{* *}$ & $28.5 \pm 2.8^{* * *}$ \\
\hline Group-V & $\begin{array}{c}\text { Barleria Montana } \\
(500 \mathrm{mg} / \mathrm{kg})\end{array}$ & $181.67 \pm 6.58 * * *$ & $147.16 \pm 11.35^{* * *}$ & $150.83 \pm 7.52 * *$ & $0.06 \pm 0.04 * * *$ & $89.1 \pm 7.1 * * *$ & $34.1 \pm 1.7 * * *$ \\
\hline
\end{tabular}

Data are expressed as Mean \pm S.E.M ( $\mathrm{n}=6$ ), One-way ANOVA Tukey posthoc; $\# \mathrm{p} \leq 0.05$ vs. Control (Group I); * $\mathrm{p} \leq 0.05$ vs. Hepatic control (Group II); ${ }^{* *} \mathrm{p} \leq 0.01$ vs. Hepatic control (Group II); *** $\mathrm{p} \leq 0.001$ vs. Hepatic control (Group II)

Table 2: Effect of Barleria Montana on antioxidant parameters on anti -TB drugs induced hepatotoxicity in rats

\begin{tabular}{|c|c|c|c|c|c|c|c|}
\hline Group & Treatment & $\begin{array}{c}\text { SOD } \\
(\mu \mathrm{moles} / \mathrm{min} / \mathrm{mg})\end{array}$ & $\begin{array}{c}\text { CAT } \\
(\mu \mathrm{mol} / \mathrm{mg} / \mathrm{min})\end{array}$ & $\begin{array}{c}\text { GPx } \\
(\mu \mathrm{mol} / \mathrm{mg} / \mathrm{min})\end{array}$ & $\begin{array}{c}\text { GRx } \\
(\mu \mathrm{mol} / \mathbf{m g} / \mathbf{m i n})\end{array}$ & $\begin{array}{c}\text { TABRS } \\
(\mathrm{nM} / \mathrm{min} / \mathbf{m g})\end{array}$ & $\begin{array}{c}\text { GSH } \\
(\mathrm{mM} / \mathrm{min} / \mathrm{mg}) \\
\end{array}$ \\
\hline Group I & Control & $3.55 \pm 0.26$ & $34.99 \pm 0.98$ & $28.99 \pm 0.64$ & $30.81 \pm 0.94$ & $34.95 \pm 1.98$ & $2.47 \pm 0.12$ \\
\hline Group II & $\begin{array}{c}\text { Anti-TB Drugs } \\
\text { (Hepatic Control) }\end{array}$ & $1.62 \pm 0.66 \#$ & $15.49 \pm 0.57 \#$ & $12.64 \pm 0.66 \#$ & $18.34 \pm 0.31 \#$ & $88.29 \pm 5.88 \#$ & $0.74 \pm 0.06 \#$ \\
\hline Group III & $\begin{array}{c}\text { Silymarin } \\
(100 \mathrm{ml} / \mathrm{kg})\end{array}$ & $3.71 \pm 0.19 * * *$ & $33.89 \pm 0.08 * *$ & $29.91 \pm 0.82 * *$ & $30.86 \pm 0.44 * * *$ & $33.89 \pm 3.23 * * *$ & $2.27 \pm 0.09 * *$ \\
\hline Group IV & $\begin{array}{c}\text { Barleria Montana } \\
(250 \mathrm{mg} / \mathrm{kg})\end{array}$ & $2.67 \pm 0.43 * *$ & $28.88 \pm 0.05 * * *$ & $23.17 \pm 0.23^{* *}$ & $25.87 \pm 0.58 * *$ & $41.98 \pm 3.07 * *$ & $1.53 \pm 0.05^{*}$ \\
\hline Group V & $\begin{array}{c}\text { Barleria Montana } \\
(500 \mathrm{mg} / \mathrm{kg})\end{array}$ & $3.27 \pm 0.04 * *$ & $34.09 \pm 0.29 * * *$ & $30.69 \pm 0.31 * * *$ & $31.11 \pm 0.26^{* * *}$ & $34.32 \pm 2.13 * * *$ & $2.37 \pm 0.04 * *$ \\
\hline
\end{tabular}

\section{RESULTS}

On acute toxicity studies

The $95 \%$ hydroalcoholic extract of Barleria Montana was found to be safe since no animal died even at the dose of $4000 \mathrm{mg} / \mathrm{kg}$ when administered orally and the animals did not show any gross behavioral changes.

\section{On Biochemical Parameters}

Animals treated with anti-TB drugs (hepatic control) showed a significantly elevated levels of SGOT, SGPT, alkaline phosphatases, total bilirubin and total cholesterol levels; and significantly decreased in HDL levels when compared to control group. 95\% hydroalcoholic extract of Barleria
Montana $250 \mathrm{mg} / \mathrm{kg}$ and $500 \mathrm{mg} / \mathrm{kg}$ given with one hour prior administration of anti-TB drugs showed a significant decreased serum diagnostic liver enzymes and increased HDL levels when compared to hepatic control. The results are presented in the Table 1.

\section{In vivo Antioxidant parameters}

In the present study, antioxidant parameters were assessed in the liver homogenate. Oral administration of anti-TB drugs (hepatic control) decreased SOD, CAT, GPx, GRx, GSH and significantly increased TBARS when compared to control group. Pretreatment of $95 \%$ hydroalcoholic extract of Barleria Montana $250 \mathrm{mg} / \mathrm{kg}$ and $500 \mathrm{mg} / \mathrm{kg}$ with one hour 
prior administration of anti-TB drugs showed significantly increased the enzymatic and non-enzymatic levels and significantly decreased TBARS levels when compared to hepatic control. The results are presented in Table 2.

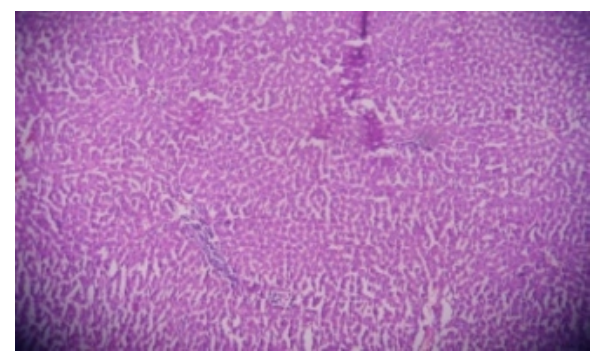

Figure 1: Control (Normal saline $1 \mathrm{ml} / \mathrm{kg}$ ) - Hepatocytes showed a normal lobular architecture of the liver

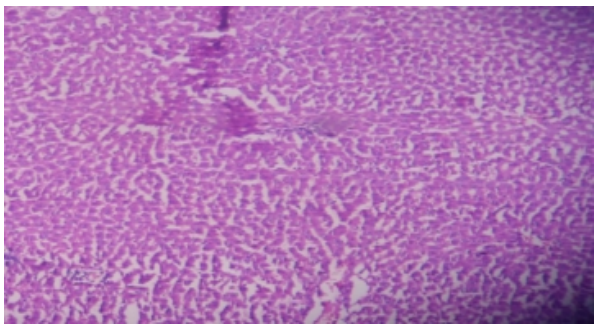

Figure 3: Standard (silymarin-100 $\mathrm{mg} / \mathrm{kg}$ ) +One hour prior administration of anti-TB drugs- Hepatocytes showed normal lobular architecture of the liver

\section{Histopathological study of the liver}

Hepatic control group animals showed significant liver cell necrosis and inflammation in the centrilobular region with portal triaditis as compared to normal control group. 95\% hydroalcoholic extract of Barleria Montana $500 \mathrm{mg} / \mathrm{kg}$ showed protective effect on the hepatocellular necrosis and their lobular structure is normal similarly like control and silymarin treated animals (Figure 1 to 5).

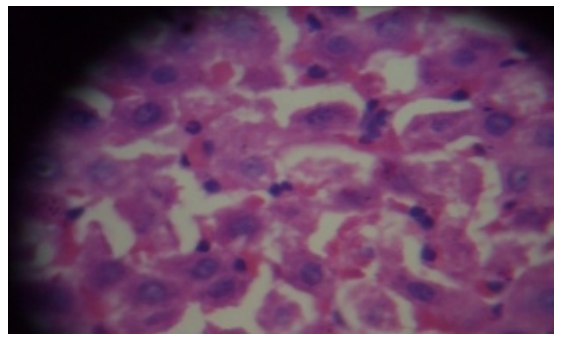

Figure 2: Hepatic control (anti-TB drugs HRZE) - Hepatocytes showed liver cell necrosis $\&$ inflammation observed in the centrilobular region with portal triaditis

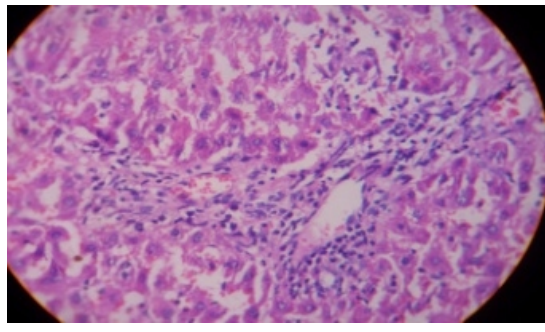

Figure 4: Group VI- (95\% hydroalcoholic extract of Barleria Montana $250 \mathrm{mg} / \mathrm{kg})+$ One hour prior administration of anti-TB drugsHepatocytes showed minimal inflammation with moderate portal triaditis and their lobular architecture is normal

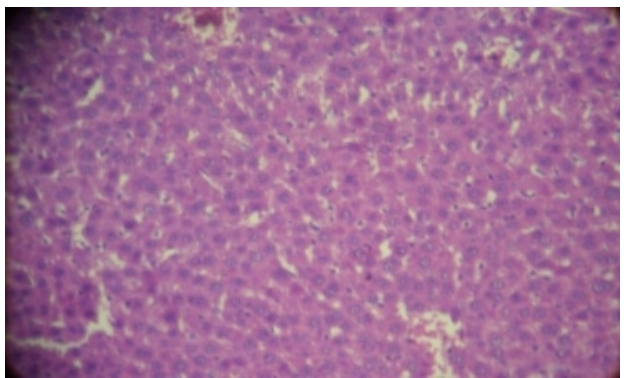

Figure 5: Group V- (95\% hydroalcoholic extract of Barleria Montana 500mg/kg) + One hour prior administration of anti-TB drugs-Hepatocytes showed group showed normal hepatocytes and their lobular architecture is normal

\section{DISCUSSION}

Anti-TB drugs like Isoniazid, Rifampicin, and pyrazinamide are independently itself are potentially hepatotoxic ${ }^{18}$, when given in combination; their toxic effect is enhanced in a synergistic manner. In the present study, the combination of anti-TB drugs is used as a tool to induce the hepatotoxicity in experimental animals ${ }^{19}$. The exact mechanisms of hepatotoxicity by these drugs are not clear, but several researchers have suggested that hepatotoxicity is mediated through release of reactive/ toxic metabolites binding covalently with liver cell macromolecules causing liver injury $^{20}$. Secondly, cytochrome P450 2E1 is involved in induction of hepatic damage ${ }^{21}$. Third reason is oxidative stress can be explained by release of free radicals, which is source for destruction and damage to cell membranes ${ }^{22}$.
Finally, an alteration of various cellular defense mechanisms involves enzymatic and non-enzymatic components such as reduced GSH have been reported in INH and RIF induced hepatotoxicity ${ }^{23}$. The reduced GSH mediated by free radical injury leads to progress in lipid peroxidation ${ }^{24}$. $95 \%$ hydroalcoholic extract of Barleria Montana is used as supplementation with anti-TB drugs to reduce hepatotoxicity caused by anti-TB drugs. In hepatic control animals elevated levels of serum diagnostic enzymes such as SGOT, SGPT and ALP levels indicate hepatic injury. At the time of hepatic injury, these enzymes leak out from liver into the blood due to the tissue damage. Pretreatment with $95 \%$ hydroalcoholic extract of Barleria Montana, the levels of these marker enzymes in serum were near normal, this may be a consequence of the stabilization of plasma membrane as well 
as repair of hepatic tissue damage caused by anti-TB drugs. Hepatotxicity is characterized by cirrhotic liver condition which in turn increased the bilirubin release ${ }^{25}$, which was observed in anti-TB drug treatment. Pretreatment with 95\% hydroalcoholic extract of Barleria Montana restored the level of bilirubin to near normal, suggesting that Barleria Montana stabilizes biliary dysfunction of rat liver. The cholesterol levels are increased which might be due to uptake of LDL from the blood by the tissues ${ }^{26}$. Thus, $95 \%$ hydroalcoholic extract of Barleria Montana may be effective on reduced cholesterol synthesis, and there by causes increased HDL levels.

The body has a defense mechanism such as enzymatic and non-enzymatic antioxidants to prevent and neutralize the free radicals induced damage. Enzymatic antioxidants like SOD and CAT play an important role in the elimination of free radicals ${ }^{27}$. The suppression of SOD and CAT activity as a result of hepatic damage ${ }^{28}$, was observed in hepatic control animals of our study also with anti-TB drugs. But 95\% hydroalcoholic extract of Barleria Montana has significantly recovered the levels of SOD and CAT, which indicates that it possess antioxidant activity. Depleted GSH level with elevated level of lipid per oxidation in anti-TB drugs were observed. Excessive lipid peroxidation can cause increase GSH consumption ${ }^{29}$. It is confirmed that from the present study $95 \%$ hydroalcoholic extract of Barleria Montana has restored hepatic GSH content by decreased lipid per oxidation levels.

Increase in the level of lipid Per oxidation in liver reflected the hepatocellular damage causes degradation of cellular macromolecules leading to tissue damage ${ }^{30}$. A marked increase in the concentration of TBARS in anti-TB drugs indicated that enhanced lipid per oxidation, failure of the antioxidant defense mechanism, and/ increase free radical production leading to oxidative stress induced cell death ${ }^{31}$. 95\% hydroalcoholic extract of Barleria Montana showed ability to prevent anti-TB drugs induced elevation of TBARS level, suggesting that Barleria Montana inhibited the hepatic lipid per oxidation. It implies that reduction in free radicals production and subsequent decrease in damage to the hepatocellular membrane.

\section{CONCLUSION}

From the results, it is clear that $95 \%$ hydroalcoholic extract of Barleria Montana has hepatoprotective activity at the dose of $500 \mathrm{mg} / \mathrm{kg}$ as compared to control and silymarin treated animals. On phytochemical investigation of $95 \%$ hydroalcoholic extract of Barleria Montana revealed the presence of flavonoids, steroids, triterpenoids, tannins and glycosides, which contributes antioxidant potential and probably this, may be responsible for hepatoprotective activity. Histopathological studies of the liver evidenced that Barleria Montana attenuated the hepatocellular necrosis and inflammation, which might be attributed to its hepatoprotective effects. Further investigations are required for the identification and isolation of constituents, which are responsible for the hepatoprotective activity.

\section{REFERENCES}

1. Akindele AJ, Ezenwanebe KO, Anunobi $\mathrm{CC} \&$ Adeyemi OO. Hepatoprotective and in vivo antioxidant effects of Byrsocarpus Coccineuss chum and thonn. (connaraceae). Journal of ethnopharmacology. 2010; 129: 46-52. http://dx.doi.org/10.1016 /j.jep.2010.02.024 PMid:20219667

2. Amat N, Upur H \& Blazekovi B. Invivo hepatoprotective activity of the aqueous extract of Artemisia absinthium L. against chemically and immunologically induced liver injuries in mice. Journal of ethnopharmacology. 2010; 131: 478-484. http://dx.doi.org/10.1016/ j.jep.2010.07.023 PMid:20637853

3. Global tuberculosis control: epidemiology, strategy, financing: WHO report 2009 (Publication no. WHO/HTM/TB/2009.411.). Geneva: World Health Organization. 2009; accessed on 28: 1, 11 .

4. Upadhyay G, Kumar A \& Singh, MP. Effect of silymarin on pyrogallol and rifampicin induced hepatotoxicity in mouse. Eur. J. Pharmacol. 2007; 565: 190-201. http://dx.doi.org/10.1016/j.ejphar.2007.03.004 PMid: 17434476

5. Sridharan Sriram and Sasikumar china gounder. Evaluation of antimicrobial activity and GC-MS profiling o Barleria Montana. Journal of pharmacy research. 2012; 5(5): 2921-2925.

6. Sridharan Sriram \& Sasikumar china gounder. Pharmacognostic standarizaiton and physicochemical analysis of the leaves of Barleria Montana wight and nees. Asian pacific journal of tropical medicine. 2012; 1: 1-3.

7. Natarajan D, Gowmathi $M$ \& Yuvarajan R. Phytochemical and antibacterial evaluation of barleria Montana nees. (mountain barleria). Asian journal of pharmaceutical and clinical research. 2012, Vol5: 3.

8. Shanazbanu, Arunachalam G, Jayaveera KN, Ashokababu VL \& Vimalkumar. Antidiabetic activity of two species of Barleria in streptozocin induced type-2 diabetic rats. Int. Res. J. Pharm. 2012; $3(10)$.

9. Shanazbanu, Arunachalam G, Jayaveera KN, Ashokababu VL. \& Premakumari. Estimation of total phenolic content and in vitro antioxidant activity of Barleria Montana. Scholar's research library, Der pharmacia letter. 2011; 3(4): 178-182.

10. OECD guidelines for the testing of chemicals revised draft guideline 423: acute oral toxicity: Paris: OECD: 2000.

11. MN Ghosh (2007). Fundamentals of experimental pharmacology.

12. Kakkar P, Das B \& Viswanathan PN. A modified spectrophotometric assay of SOD. Indian Journal of Biochemistry Biophysics. 1984; 2: 130132.

13. Aebi H. Catalase in vitro. Methods in Enzymology. 1984; 105: 121-126. http://dx.doi.org/10.1016/S0076-6879(84)05016-3

14. Sener G, Sehirli AO, Gedik N \& Dulger GA. Rosiglitazone, a PPAR- $\gamma$ ligand, protects against burn-induced oxidative injury of remote organs. Burns. 2007; 33: 587-593. http://dx.doi.org/10.1016/j.burns.2006.10.381 PMid: 17467912

15. Paglia DE \& Valentine WN. Studies on the quantitative and qualitative characterization of erythrocytes glutathione peroxidase. J. Lab. Clin. Med. 1986; 40: 158-69.

16. Racker E. Glutathione reductase from bakers' yeast and beef liver.The Journal of Biological Chemistry. 1955; 217: 855-866. PMid: 13271446

17. Rukkumani R, Aruna K, Varma PS, Rajasekaran KN \& Menon VP. Comparative effects of curcumin and an analogue of curcumin on alcohol and PUFA induced oxidative stress. Journal of Pharmacy \& Pharmaceutical Sciences. 2004; 7: 274-283. PMid: 15367386

18. Kaneko, Nagayama N, Kawabe Y, Shimada M, Suzuki J \& Kunogi M et al. Drug induced hepatotoxicity caused by antituberculous drugs in tuberculosis patients complicated with chronic hepatitis, Kekkaku. 2008; 83: 13-9. PMid: 18283910

19. Saraswathy SD, Suja V, Gurumurthy \& Shyamala devi CS. Effect of Liv.100 against anti-tuberculosis drugs (isoniazid, rifampicin and pyrazinamide) induced hepatotoxicity in rats. Indian J Pharmacol. 1998; 30: 233 .

20. Noda A, Hso KY, Noda H, Yamamoto Y \& Kurozumi T. Is isoniazidhepatotoxicity induced by the metabolite, hydrazine. JUOEH. 1983; 5: 183-90. PMid:6679629

21. Salem TSM, Christina AJM, Chidambaranathan N, Ravi V \& Gauthaman K. Hepatoprotective activity of Annona Squamosa Linn. On experimental animal model. Int. J. Appl. Res. Nat. Pro. 2008; 1(3): 1-7.

22. Evans IS, Sahar ME, Mabrouka OS \& Azza EB. Role of oxidative stress and nitric oxide in the protective effects of lipoic acid and aminoguanide against isoniazid -rifampicin induced hepatotoxicity in rats. Food chem. Toxicol. 2010; 48: 1869-1875. http://dx.doi.org/ 10.1016/j.fct.2010.04.026 PMid:20417245

23. Chowdary A, Santra A, Bhattachajee K, Ghatak S, Saha DR, \& Dahli GK. Mitochondrial oxidative stress and permeability transition in isoniazid and rifampicin induced liver injury in mice. J Hepatol. 2006; 45:117-126.http://dx.doi.org/10.1016/j.jhep.2006.01.027 PMid:16545483

24. Nasim Ilyas, M Sadiq \& Adnan Jehangir. Hepatoprotective effect of garlic (Allium Sativum) and milk thirstle (silymarin) in isoniazid induced hepatotoxic in rats, D:/Biomedica. 2011; Vol.27: Jul-Dec.

25. Yuen MF, Kato T, Mizokami M, Chan AO, Yuen JC, Yuen HJ et al. Clinical outcome and virology profiles of severe hepatitis B exacerbation due to YMDD mutations. J Hepatol. 2003; 39: 850-5. http://dx.doi.org/10.1016/S0168-8278(03)00388-X

26. Kissler HJ, Hauffen J, Hennig R, Gepp H \& Schwille PO. Glucose and lipid metabolism after liver transplantation in inbred rats: Consequences 
of hepatic denervation, Metabolism. 2005; 54: 881-890. http:// dx.doi.org/10.1016/j.metabol.2005.01.036 PMid:15988696

27. Amresh G, Rao CV \& Singh PN. Antioxidant activity of Cissampelos pareira on benzo (a) pyrene induced mucosal injury in mice. Nutr Res. 2007; 27: 625-632. http://dx.doi.org/10.1016/j.nutres.2007.05.009

28. Duairaj AK, Vaiyapuri TS, Mazumder UK \& Guptam. Hepatoprotective activity of Oxysetelma esculentum in paracetmol induced liver damage in rats. Pharmacologyonline. 2007; 3: 52-72.

29. Onyema OO, Farombi EO, Emerole GO, Ukoha AI \& Onyeze GO. Effect of vitamin $\mathrm{E}$ on monosodium glutamate induced hepatotoxicity and oxidative stress in rats. Indian J Biochem Biophys. 2006; 43: 20-24. PMid: 16955747

30. Hussain Tabib, Gupta K Ramesh, K Sweety, Mohd Sajid, Khan Md Sarfaraj Hussain, Md Arif, Hussain Arshad, Md Faiyazuddin \& Rao
Chandana Venkateswara. Evaluation of antihepatotoxic potential of Solanum xanthocarpum fruit extract against antitubercular drugs induced hepatopathy in experimental rodents. Asian Pacific Journal of Tropical Biomedicine; 2012:454-460. PMCid:3609318

31. Santosh S, Sini TK, Anandan R \& Mathew PT. Hepatoprotective activity of chitosan against isoniazid and rifampicin induced toxicity in experimental rats. Eur J Pharmacol. 2007; 572: 69-73. http:// dx.doi.org/10.1016/j.ejphar.2007; 05: 059 PMid:17612523

\section{Cite this article as:}

Jyothi Basini, S. Mohana lakshmi, K. Anitha. Antihepatotoxic effect of Barleria montana leaves against Anti-TB drugs induced hepatotoxicity. Int. Res. J. Pharm. 2013; 4(6):97-101 